\title{
Newborn Screening for Critical Congenital Heart Disease: Appropriately Evaluating This Public Health Program
}

\author{
Matthew E. Oster ${ }^{1,2}$ (D) $\cdot$ Gerard R. Martin ${ }^{3}$
}

Received: 6 March 2020 / Accepted: 14 May 2020 / Published online: 30 May 2020

○) Springer Science+Business Media, LLC, part of Springer Nature 2020

It was with great interest that we read "Pulse Oximetry Screening Has Not Changed the Timing of Diagnosis or Mortality of Critical Congenital Heart Disease" by Campbell et al. [1]. The authors have done an admirable job of describing how newborn screening for critical congenital heart disease (CCHD) has affected surgical outcomes at their center. However, we advise caution in interpreting these findings as an assessment of the overall impact of this public health program.

First, using clinical data from a single referral center is not an ideal way to evaluate a public health program. A true public health assessment would be population-based, would be indexed to the birth rate for the period in question, and would identify not just those referred for surgery but also those missed by screening (false negatives). Indeed, many state agencies are trying to perform such assessments, but further help is needed in capturing the necessary data [2].

Second, the study lacked statistical power to detect significant differences due to the very small numbers of CCHD cases that could have benefited from screening at $24 \mathrm{~h}$. Approximately $77 \%$ of the cases were detected prenatally, and many of the remaining $23 \%$ were likely detected prior to $24 \mathrm{~h}$ of age. We estimate that their sample size afforded them at most $4 \%$, $7 \%$, and $16 \%$ power to detect 1 -year mortality decreases of $10 \%, 25 \%$, and $50 \%$, respectively. Furthermore, the authors had no way of accounting for cases that failed screening but died prior to presenting for surgical repair. The authors acknowledge these limitations in their manuscript, but these major limitations underscore the importance of using data from multiple centers or, ideally, an entire population-defined area.

Finally, the authors' critique that the study by Abouk et al. could not account for the impact of improvements in

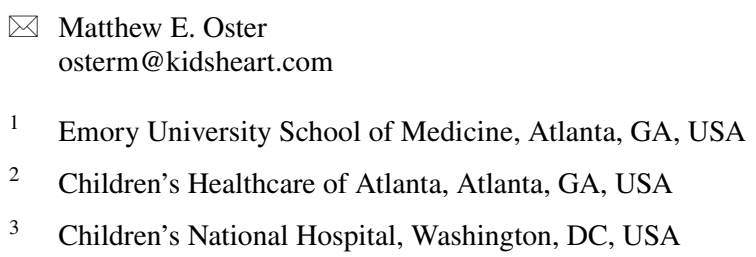

clinical management on improved survival is misleading. The difference-in-differences analysis by Abouk et al. used contemporary controls to account for both state-specific and time-variant factors [3]. Only if there were a strong temporal association between implementation of state CCHD screening mandates and clinical improvements specific to CCHD management varying by state could clinical improvements have affected the results.

Newborn screening for CCHD has been a public health success [4]. Yet, as with any program, its impact is expected to vary between centers and states. Thus, using population-level data to assess outcomes of population-wide interventions is preferable to using single-center data using historical controls.

\section{Compliance with Ethical Standards}

Conflict of interest The authors declare that they have no conflict of interest.

\section{References}

1. Campbell MJ, Quarshie WO, Faerber J, Goldberg DJ, Mascio CE, Blinder JJ (2020) Pulse oximetry screening has not changed timing of diagnosis or mortality of critical congenital heart disease. Pediatr Cardiol. https://doi.org/10.1007/s00246-020-02330-1

2. Oster ME, Aucott SW, Glidewell J, Hackell J, Kochilas L, Martin GR, Phillippi J, Pinto NM, Saarinen A, Sontag M, Kemper AR (2016) Lessons learned from newborn screening for critical congenital heart defects. Pediatrics 137(5):e20154573

3. Abouk R, Grosse SD, Ailes EC, Oster ME (2017) Association of US state implementation of newborn screening policies for critical congenital heart disease with early infant cardiac deaths. JAMA 318:2111-2118

4. Kemper AR, Lam WKK, Bocchini Jr JA (2017) The success of state newborn screening policies for critical congenital heart disease. JAMA 318:2087-2088

Publisher's Note Springer Nature remains neutral with regard to jurisdictional claims in published maps and institutional affiliations. 